\title{
Integrated reporting and narrative accountability: The role of preparers
}

Purpose-The International Integrated Reporting Council (IIRC) claims that integrated reporting (IR) can enhance corporate accountability, yet critical and interpretative studies have contested this outcome. Insufficient empirical research details how preparers experience accountability while constructing IR; to fill this gap, this study analyses how the preparers' mode of cognition influences the patterns of accountability associated with IR.

Design/methodology/approach-A functionalist approach to narratives helps elucidate the role that the IR preparers' narrative mode of cognition plays on accountability toward stakeholders. The empirical analysis particularly benefits from in-depth interviews with the IR preparers of a global insurer that has used IR since 2013.

Findings-The preparers' narrative mode of cognition facilitates dialogue with IR users. It addresses accountability tensions by revealing the company's value creation process. Preparers' efforts to establish a meaningful dialogue with a growing variety of stakeholders through broader and plainer messages reveals the potential of IR as a narrative source of a socializing form of accountability. However, financial stakeholders remain the primary addressees of the reports.

Research limitations/implications-This study focuses on preparers' views; further research should integrate users' accountability expectations.

Originality/value-This article offers new insights for dealing with corporate reporting and accountability in a novel IR setting.

Keywords-Integrated reporting, Accountability, Narratives, Report preparers, Mode of cognition, Insurance.

Paper type-Research paper 


\section{Introduction}

The emergence of integrated reporting $(\mathrm{IR})^{1}$ principles, frameworks and corporate practices (de Villiers et al., 2014, 2015, 2016; Dumay et al., 2016) has prompted divisive debate about whether and how such reporting standards might enhance corporate accountability. The International Integrated Reporting Council (IIRC), the primary promoter of IR as an international voluntary disclosure practice, asserts that such emerging practices will "enhance accountability" by soliciting disclosures about "how key stakeholders' legitimate needs and interests are understood, taken into account, and responded to through decisions, actions, and performance, as well as on-going communication" (IIRC, 2013a, p. 18, § 3.14). In this view, IR can "[e]nhance accountability ... for the broad base of capitals (financial, manufactured, intellectual, human, social and relationship, and natural)" (IIRC, 2013a, p. 2).

Yet many studies challenge these claims (e.g., Brown and Dillard, 2014; Flower, 2015; Thomson, 2015). For example, Deegan (2013, p. 457) argues that the IIRC, by explicitly adopting financial reporting conventions, focused on the information demands of capital providers, "counters any real likelihood of providing a useful framework for broad-based accountability," because IR offers limited ability to address the decision-making and accountability needs of other stakeholders (Brown and Dillard, 2014). Close connections between preparers and investors also might limit its potential to help stakeholders understand nonfinancial impacts or hold managers accountable (de Villiers et al., 2014). Only a few scholars take a more optimistic view and predict that IR can redefine corporate accountability (Busco et al., 2013; Adams 2015).

A growing number of studies offer in-depth assessments of IR practices, including those published in a 2014 special issue of Accounting, Auditing and Accountability Journal, yet no previous research empirically investigates the accountability experience of IR preparers during the process of IR construction. Rather, the debate about the possibilities of IR for enhancing corporate accountability has remained conceptual and focused on the (changing) content and scope of the International Integrated Reporting Framework (IIRF) (Flower, 2015).

Some critical and interpretative research argues that narrative forms of accountability facilitate dialogue between accountors and accountees more than does calculative accountability, which is based on numbers (Boland and Schultze, 1996; McKernan and McPhail, 2012). Boland and Schultze (1996) suggest that the ability to enter into a dialogue with addressees, in accordance with so-called socializing forms of accountability (Roberts, 1991, 1996), depends on preparers' modes of cognition. Calculative (or paradigmatic) content, based on calculative or paradigmatic cognition, limits dialogue and produces more individualizing forms of accountability, because the accountor does not seek meaningful dialogue. More narrative content, based on narrative cognition, instead

\footnotetext{
${ }^{1}$ In this article, the acronym "IR" refers both to integrated reporting, or the process of preparing an integrated report, and the integrated report itself, which is the outcome of this process. The context determines the meaning in each instance.
} 
facilitates socializing forms of accountability, by favouring meaningful dialogue.

Emerging research underlines the narrative nature of IR (Beattie, 2014), signalling a broader "move towards integrated, narrative-based reporting around the central business model story" (Beattie and Smith, 2013, p. 118). Some preparers even refer to IR as strategic storytelling that allows "the company story to be told in a way that it has not been told before" (Higgins et al., 2014, p. 1102). However, no prior studies explore its potential as a narrative source of a socializing form of accountability toward investors and other stakeholders. The possibility that IR may facilitate a meaningful dialogue between preparers and users by stimulating the preparers' narrative mode of cognition has not been investigated, either conceptually or empirically. To fill this gap, the current article empirically explores how the preparers of an IR pioneer experienced accountability while producing the IR. These preparers' narrative mode of cognition influenced the patterns of accountability associated with their IR and its potential to favour socializing accountability. A functionalist approach to narratives analysis, as depicted by the psychologist Jerome $\mathrm{S}$. Bruner (1986, 1990, 1991) - whose work also informed Boland and Schultze's (1996) argument - helps elucidate how a narrative mode of cognition works to address accountability tensions and challenges.

Assicurazioni Generali S.p.A. (hereafter, Generali or the Company) serves as the empirical case for the analysis. Generali embraced the project established by the IIRC in 2011. It joined the IIRC pilot program in 2012, actively participates in three IIRC business networks (business, insurance, and national network of Italian IR adopters), and has published four annual IRs (2013, 2014, 2015, and 2016), in accordance with the IIRF (2013a). Several in-depth interviews with Generali staff involved in the IR implementation and reviews of the four annual IRs provide the key empirical material to inform a detailed description of how preparers' modes of cognition can influence patterns of accountability enabled by the IR. The potential for unveiling such connections is a matter of interest for both academics and practitioners engaged in understanding whether and how IR can enhance corporate accountability toward investors and other stakeholders, as well as what role preparers actually play in this process.

Section 2 theoretically frames the present study according to accountability literature, and Section 3 provides a review of pertinent accounting research on IR. Section 4 contains a description of the methodology; Section 5 introduces the case study company and its IR, followed by the empirical findings in Section 6. Finally, Section 7 discusses the findings, and Section 8 concludes by highlighting the study contributions and limitations.

\section{Accountability and corporate external reporting: theoretical frame}

With its multiple meanings (Sinclair, 1995), accountability regularly appears in accounting literature (Messner, 2009). A generic, sociological meaning refers to "the giving and demanding of reasons for conduct" (Roberts and Scapens, 1885, p. 447), which entails explanation, justification, 
and taking responsibility for one's own conduct (Roberts and Scapens, 1885). In exploring the content of accountability (i.e., accounts that an accountor provides to an addressee) and the social practice of giving and demanding accounts (i.e., procedures for providing accounts), critical/interpretative accounting scholars particularly seek to understand the experiences and practical engagement of actors involved in accountability relationships (e.g., Gray et al., 1988; Roberts, 1991; Messner, 2009).

For corporate external reporting, the addressee usually is located outside the organization, and the organization provides some explanation of what it has done or not. Discharging accountability entails the publication of mandatory or voluntary reports. Scholars critically exploring the limits of accountability in terms of content suggest the need to extend traditional forms beyond providing financial accounts, to institutionalise “'alternative accountings' in which [corporate] 'externalities' [e.g. environmental degradation] are central” (Gray, 2006, p. 798). Despite some concerns about how companies actually engage with "substantive accountability reporting," such reporting seemingly could offer "a first significant and sensible step to begin to expose the extent to which the potential doomsday scenarios are worthy of our attention or not" (Gray, 2006, p. 810). Debate about corporate reporting thus has expanded to include the viability or usefulness of business model disclosures in financial statements or other outlets (Page, 2014; Melloni et al., 2016).

Critical scholars who go beyond an appreciation of the (financial and nonfinancial) nature of accountability contents also express some concern that a narrative mode of accountability, with its narratives and storytelling, "is consistently undervalued and often suppressed" (Boland and Schultze, 1996, p. 62). Instead, accountability based on numbers (or calculative accountability) is more prevalent in corporate reporting, in line with the idea that "numbers ... speak for themselves, no interpretation needed, no narrative required, and the only story a 'story of no story to tell"' (McKernan and McPhail, 2012, p. 179). Yet an "increasing reliance on narratives in the business reporting package" (Beattie, 2014, p. 121) is clearly demonstrated in the International Accounting Standard Board (IASB) project on management commentary (IASB, 2010) and similar initiatives (e.g., EFRAG, 2013). The IIRC project moves in a similar direction; it solicits storytelling forms of reporting (Higgings et al., 2014), as also detailed in the memorandum of understanding signed by the IIRC and the IASB (IASB and IIRC, 2013).

As highlighted by Beattie (2014), this narrative turn has led shareholder reports to be interpreted as investment "story" (Jameson, 2000) and stimulated the use of the metaphor "story" in relation to accounting narratives aimed at describing various value creation processes (Holland, 2005). Corporate storytellings are considered to enhance dialogue with investors and analysts (PwC, 2007). These studies underscore the discretion underneath the narrative content. Beattie (2014, $\mathrm{p}$. 118) claims that research should not only try to demonstrate the use of stories in accounting narratives. Scholars should offer "more finely nuanced explanations of the set of circumstances" influencing the nature of these forms of reporting. She concludes by arguing that "the investigation 
of author-narrator explanations of why they provide narratives ... [is] the province of the interpretive/critical approach" (Beattie, 2014, p. 127). To the best of our knowledge, no previous studies have taken this approach to empirically explore IR narratives.

Studies that focus on procedural aspects of accountability (Messner, 2009, p. 922) seek to connect the content of accountability to the ways addressors construct relationships with addressees, such as involving them in dialogue or keeping them more distant (e.g., Roberts, 1991, 1996; Boland and Schultze, 1996; Shearer, 2002; McKernan and MacLullich, 2004). Shearer (2002) suggests that enriching (financial) accounting with social and environmental accounting may help establish a broader perspective, based on the recognition of others' demands. Roberts (1991) and McKernan and MacLullich (2004) appear more sceptical and call instead for methods that can enrich the procedure through socializing forms of informal accountability, based on face-to-face encounters (Roberts, 1991, 1996).

Along these lines, Boland and Schultze (1996) detail a theoretical connection between the content and procedural dimensions of corporate accountability, arguing that the construction of corporate accountability relies on an addressor's modes of cognition. The narrative mode of cognition (Bruner, 1986) is the primary source for socializing forms of accountability, because the narrator constructs a meaningful dialogue with the addressee: "[N]arration as a mode of cognition is the principle occasion for socially constructing an accountable self and a world in which accountability is expected" (Boland and Schultze, 1996, p. 65). The possibilities for establishing a dialogue with accountees rely on the accountors' capability to tell a story: A narrative capacity, or "ability to narrate their experience and that of others in making sense of the world" (Boland and Schultze, 1996, p. 64), is required of accountors that want to induce socializing effects. In other words, narrators should be able to select and combine (Bruner, 1986) the elements of the story plot in a way that makes the story plausible, believable, and meaningful. This ability facilitates dialogue, by leading accountors to recognize others' needs. According to Bruner (1990), the function of a narrative is to explain unexpected or anomalous events, by recasting them in a story-based format that makes the rare experiences seem safer or more familiar. In serving this function, the narrative solves problems, reduces tensions, and resolves dilemmas (Bruner, 1990); in the Boland and Schultze's (1996) view, such a narrative is able to produce socializing accountability effects.

Although they regard narrative and paradigmatic means to explain phenomena as inseparable, Boland and Schultze (1996) contest any strict relationship between the computational and storytelling roots of accountability and its individualizing and socializing forms, respectively. Information technologies (e.g., Lotus Notes groupware database) can shape accountability dialogues by stimulating a narrative mode of cognition, so they argue that socializing forms of accountability exist even in formal/hierarchical contexts, such that the mode of cognition, not specific media, moulds the relationship between the accountor and accountee. A paradigmatic form of cognition (Bruner, 1986), based on computation and argumentations, is not sufficient to establish 
dialogue and instead may create distance (i.e., individualizing forms of accountability; Roberts, 1991, 1996).

In corporate reporting, addressees include investors (or capital providers) and other stakeholders (e.g., employees, customers, strategic partners). Because investors are the only external stakeholders "who can even vaguely be assumed to have a familiarity with financial statements" though (Gray et al., 1988, p. 10), the complexity of financial reporting may limit the engagement of other stakeholders (Gray, 2006, p. 795). Yet designing social and environmental reporting "for use by investors appears to be highly questionable ... investors are likely to be almost entirely uninterested in corporate social responsibility except in so far as it influences their financial position" (Gray et al., 1988, pp. 10-11; see also Rinaldi et al., 2014). Drawing on Boland and Schultze's (1996) arguments, this article investigates how the preparation of the IR, by soliciting the preparers' narrative modes of cognition, facilitates dialogue between preparers and intended addressees of the report.

\section{Accountability and IR: previous studies}

\subsection{Narrative nature of IR}

The voluntary disclosure practice of IR has gained momentum since the 2010 formation of the IIRC (De Villiers et al., 2014). Its importance is linked to the increased demand for narratives in business reports, including information about value creation over time that rarely appears in financial statements (Beattie, 2014). It also stems from complaints about the length and complexity of financial statements, which tend to be difficult to understand (Beattie, 2014). The IIRC aimed to develop a new global reporting framework that could simplify company reporting while still providing insights into value creation.

The IIRF, published in December 2013, defines the IR as a "concise representation of how an organization's strategy, governance, performance and prospects, in the context of its external environment, lead to value creation over time" (IIRC, 2013a, p.7). The IR represents a periodic report about value creation story that provides "a mean to assess the plausibility of what has been reported concerning the present-to-future period [and for] analysing current capabilities and the quality of management" (IIRC, 2013a, p.17). Furthermore, the IIRF stresses the importance of the language used in the IR, requiring that it "ex press concepts clearly, in as few words as possible ... and favours plain language over the use of jargon or highly technical terminology" (IIRC, 2013a, p.21).

Previous research supports this narrative approach, suggesting that the IIRF offers "a new reporting framework focused on firms' future value creation narrative" (de Villiers et al., 2016, p.1) and that the "IR formalises the story concept by signalling a move toward narrative based reporting" (Beattie and Smith, 2013, p. 118). Higgins et al. (2014) show that preparers regard IR as a way to tell the firm's story and resolve strategic communication challenges. According to Lodhia (2015), study preparers recognize IR as an opportunity to tell their real story, and for "IR to play this role most effectively, ... there is merit in bringing together the new science of reporting and the ancient 
art of storytelling" (O'Hearne and Pauffley, 2014, p. 12). In this sense, "IR offers a new opportunity and the best possible way now available to tell the value creation story" (CIMA et al., 2014, p.3). Lueg et al. (2016) explain IR as an instrument to enhance corporate communication by merging existing sub-reports (e.g., annual reports, sustainability reports), using less technical language and concentrating on material aspects.

As a principle-based framework, the IIRF permits discretion about how to build narratives and tell the value creation story. Although IR should tell "a firm's value creation narrative going forward, by specifically referring to corporate strategy, how the strategy translates into a firm's business model and how the business model takes advantage of the six forms of capital to create or destroy value" (de Villiers et al., 2016, p.3), its different ingredients (e.g., strategy, business model, corporate governance, performance, prospects) could be combined in diverse ways. Managers' discretion in turn makes it difficult to determine whether and to what extent a firm complies with the IIRC framework, with consequent challenges to IR assurance, regulation, and research (de Villiers et al., 2016, Cheng et al., 2014). Such discretion and uncertainty stem from the principle-based nature but also the changing meaning of IR over time (Flower, 2015).

Many studies also criticise the IIRF for diverging from sustainability and accountability roots (Brown and Dillard, 2014; Cheng et al., 2014; Flower, 2015; Thomson, 2015). This shift in logic has implications for how IR narratives are forged and related accountability patterns. The IR constitutes an accounting-sustainability hybrid practice that "builds on the strengths of accounting, such as robust quantitative evidence gathering, relevance, materiality, reliability, comparability and assurability, to translate the sustainability discourse into a 'language' understandable to organisational decision-makers" (Thomson, 2015, p. 19). It therefore reflects growing acceptance that social and environmental issues have moved beyond being dismissed as "nonfinancial," "soft," or "qualitative" and instead are perceived as "material" and "financial" in nature (Atkins and Maroun, 2015).

While prior research on accounting narratives has elucidated the narrative potential in enhancing accountability towards various stakeholders (see Section 2), to the best of our knowledge there are no studies on how IR narratives can actually favour this effect and what is the role of preparers' mode of cognition in this process.

\subsection{IR and accountability addressees}

IR should increase accountability for broad bases of capital, financial and nonfinancial (i.e., manufactured, intellectual, human, social, relationship, natural; IIRC, 2013a), by disclosing how key stakeholders' legitimate needs and interests are understood, taken into account, and responded to through decisions, actions, and performance, as well as on-going communication (IIRC, 2013a). In this sense, IR may presume an ability and willingness to embark on a dialogue with a broad base of stakeholders, not just financial capital providers. By requiring the disclosure of key stakeholder 
relationships, the IIRC encourages consideration of such impacts and responses (Busco et al., 2013, Adams, 2015). The report may bring about socializing accountability to a wide range of stakeholders, including but not limited to shareholders.

Yet previous studies often present the IR concept as a limited approach that fails to ensure accountability for those other stakeholders (Brown and Dillard 2014; Flower 2015; Thomson, 2015). According to Milne and Gray (2013, p. 25), the IIRC's proposals are "remarkably regressive" and exhibit a strong investor bias, with no attempt to discuss issues of corporate accountability. Although early discussion papers of the IIRF emphasised firms' sustainability and accountability to a broader group of stakeholders, the final IIRF identifies value creation for financial capital providers as fundamental to IR preparation (de Villiers et al., 2016, Flower, 2015). That is, IR responds to the need to be accountable to investors, providing more relevant narrative and nonfinancial information that enables them to appraise corporate value (Rowbottom and Locke, 2016). The primary focus of the IIRC is indeed the information needs of capital providers, so a company is unlikely to trade off different forms of financial and nonfinancial capital, in line with IR as a stakeholder-centric reporting mechanism (de Villiers et al., 2016). This strong market orientation might result from a lack of stakeholder engagement in the development of the framework, in which case the IIRF fails to reflect broad-based users' information needs (Reuter and Messner, 2015).

Stakeholders may hold different views about what IR should emphasise, relative to investors (Van Bommel, 2014; Flower, 2015) and if IR seeks to discharge accountability duties mainly connected to financial value creation, its potential to help them understand social and environmental impacts and hold managers accountable for them would be relatively limited (De Villiers et al., 2014). By adopting key financial reporting conventions, and linking materiality to value creation, IR might not extend the accountability of organizations, either in terms of nonfinancial aspects of their operations or to nonfinancial stakeholders; nor does broader accountability necessarily occur through the voluntary provision of new information (Deegan, 2013). Brown and Dillard (2014) claim that because IR actually centres more on stakeholder management than on stakeholder accountability, it reinforces business-as-usual, rather than broader, more open dialogues with stakeholders such as consumers, employees, suppliers, local communities, labour unions, social movements, governments, indigenous communities, developing countries, and future generations.

Investigations of IR's potential to enhance corporate accountability remain conceptual and focused on the content and scope of the IIRF (Flower, 2015, Adams, 2015, Thomson, 2015), rather than the experiences or actual engagement of actors involved in accountability relationships. A few exceptions are notable: Stubbs and Higgins (2014) sought perspectives from both finance and sustainability managers and find that despite a lack of fundamental change, early IR adopters exhibit a more holistic approach, with more engagement among internal stakeholders, such as financial and sustainability groups. Beck et al. (2015) also note the IR journey of a large Australian financial corporation that did not fully conform with the objective of the IIRC, particularly with respect to its 
narrow identification of target stakeholders, but conceived of IR as an instrument to communicate with broad ranges of stakeholders. With their focus on the role of preparers, these studies suggest that IR narratives can extend accountability, though empirical studies question this outcome. For example, Higgins et al. (2014) show that financial stakeholders remain primarily significant to IR preparers, and other stakeholders are assigned passive positions, with the assumption that their needs are the same as those of the financial actors (see also Lodhia, 2015).

Accountability efforts in IR narratives thus appear influenced more by the preparers' views than by the IIRF (Thomson et al., 2014). Chaidali and Jones (2017) similarly highlight the importance of engaging with IR preparers and understanding their specific views to document the development of the IR. Accordingly, this study addresses the role of preparers' narrative modes of cognition and its influence on the patterns of accountability associated with IR.

\section{Methodology}

\subsection{Analytical approach}

This research adopts a functionalist approach to narrative analysis (Bruner, 1986; 1990; 1991). Postulating that narrators' narrative mode of cognition and resultant narrative representation cannot be interpreted separately (Bruner, 1991, p. 5; see also Bruner, 1990; Boland and Schultze, 1996), a functionalist approach highlights the interpretations that narrators offer of the events that they nestle in the narrative, rather than its structural elements (Coghlan and Brydon-Miller, 2014). Such an analysis investigates the function that the narrative (mode of cognition) serves, in helping people make sense of their lives, particularly by shaping chaotic, unexpected, or anomalous events into a coherent story. The narrative (mode of cognition) might solve various functions, such as dealing with problems, reducing tensions, or resolving dilemmas (Bruner, 1990; see also Ignatow and Mihalcea, 2016). There are a number of ways in which this may occur. One of the narrative features (i.e. the so-called "grammatical constituents" in Bruner's [1990, p. 77] work) that make a story "tellable" is associated with the mismatch between the exceptional and the ordinary. The narrators should be able to explain exceptional, unexpected or anomalous events, by recasting them in a story-based format that makes the rare experiences seem safer or more familiar. A narrative (mode of cognition) may also display "agentivity," such that it shows objectives that can be controlled by human actors; include a sequential order of events, mental states, and happenings that involve human beings as characters or actors; and highlight the narrator's perspective on the actions and intentions of the characters. In interpreting the narrative (mode of cognition) and how it solves its functions, researchers are required to interpret the "components" of a story as "functions" of this story rather than autonomous "themes" or "elements" (Bruner, 1990, p. 80), thus investigating why and how narrators select and combine these components (Bruner, 1986).

To uncover how IR preparers' mode of cognition influences the patterns of accountability associated with this form of reporting, the present research explores how the narrative mode of 
cognition helps preparers address accountability tensions and challenges. The narrative and paradigmatic modes of cognition are intertwined (Boland and Schultze, 1996), but this study focuses on the narrative mode to inspect how it facilitates socializing accountability effects. Accordingly, this study operationalizes the narrative mode of cognition according to the above mentioned narrative features that help a narrative serve its functions (i.e., for IR preparers, to address accountability tensions and challenges). The preparers' mode of cognition should inform the functions ascribed to the IR, and the socializing accountability effects that derive from this capability of IR to address accountability tensions and challenges can be explored in terms of the dialogue that gets created or enhanced with addressees of the IR. In line with previous studies of accountability, corporate reporting (e.g., Gray et al., 1998; Gray, 2006; O'Dywer and Unerman, 2008), and IR users (e.g., Deegan, 2013; Brown and Dillard, 2014; Flower, 2015; Thomson, 2015), this study distinguishes IR users as financial (e.g., investors, analysts) or nonfinancial (e.g., customers, employees) stakeholders.

\subsection{Data collection}

This analysis draws on interviews with Generali actors who are directly or indirectly involved in the IR implementation. While Generali explicitly agreed that the company could be identified in any paper from the research, we guaranteed privacy and anonymity to our informants. We ran 17 in-depth semi-structured interviews (16 hours - the average length of the interviews was of 56 minutes) with Generali's staff (ten different people generically identified as "staff" and numbered in order of appearance in the findings section). At the time of the interviews, the interviewees' seniority ranged from one to nineteen years.

The interviews, conducted between September 2015 and January 2017, took place in dedicated meetings with the authors or following IR presentations to various panels (e.g., public presentations, insurance group meetings, university presentations to students, televised debates), at which the authors were officially present. We informed the interviewees about the general research purpose (i.e., writing a paper on Generali's experience in IR). The authors obtained permission to record the questions and answers during the interviews and use them for research purposes. In some cases, the interviewees requested the deletion of select parts of their responses, which was always granted. Table 1 contains a list of the main issues covered during the interviews.

\section{Insert Table 1 here}

The four annual IR produced by the Company for the 2013-2016 financial years also form the basis of the analysis. These additional sources offer information pertinent to the organizational and reporting contexts (e.g., corporate documentation tracing Generali's shift toward IR, organizational structure and governance system, insurance sector, IIRF). 


\subsection{Data analysis}

According to prior research on accounting narratives (e.g. Llewellyn, 1996; Beattie, 2014), both the interview transcripts and the IR texts are used as "narratives" to be analysed according to the Bruner's (1986; 1990; 1991) functionalist approach.

The analysis started with an effort to detect the function assigned to IR by its preparers, through a review of the interview transcripts to reveal accountability tensions and challenges that the preparers sought to face with the IR. To trace these tensions and challenges, the assessments of the interview transcripts included careful attention paid to the motivations for the IR adoption. Next, the analysis continued with an exploration of how the narrative mode of cognition enabled IR to serve an assigned function, in line with Bruner's (1990) four narrative "grammatical constituents". Drawing on his functional approach, we particularly focused on understanding why and how preparers select and combine content elements (i.e. the "components" of the story), according to the function assigned to the report.

Using Boland and Schultze's (1996) description of the forms of accountability as a reference point, the subsequent step explored patterns of accountability enabled by the IR, with a particular focus on detecting traces of socializing forms of accountability (Boland and Schultze, 1996; Roberts, 1991, 1996), stimulated by IR. The author team looked for preparers' explanations of how they enhanced or created dialogue, mutual understanding, and interaction with various stakeholders.

Finally, when analysing the transcripts (manually transcribed in their original language, English or Italian), care was taken to ensure traceability throughout the subsequent analysis, to mitigate concerns about methodological rigour or the subjectivity of such analyses. In particular, the transcript analysis entailed consideration of the role of any external consultants. The interviewees clearly indicated that IR content choices are internal, such that external consultants were limited to creating a layout, following their recommendation. Thus the possibility of bias is minimal, and external consultants do not serve as IR "preparers" who might affect the IR narratives.

\section{The Company and its IR}

Founded in 1831, Generali is the largest insurance group in Italy and third in the world. Its headquarters are in the north-eastern city of Trieste. With 76,000 employees, 530 billion euro in assets under management, and 55 million customers, it is one of the 50 largest companies in the world. Generali offers services for the life and property and casualty insurance segments; it operates in more than 60 countries using more than 430 companies. It is the market leader in Italy, has a strong presence in Europe, and aims to increase its presence in Asia and South America. Generali belongs to the Euro Stoxx 50 stock market index.

The journey of Generali toward IR starts in 2012, when it joined the official IIRC pilot programme, then published its first annual IR in 2013. Since then, it has published three more annual IRs $(2014,2015$, and 2016). Its commitment to the IIRC is manifest in its participation in the $<\mathrm{IR}>$ 
Business Network, which is a continuation of the $<\mathrm{IR}>$ Pilot Programme that officially ended in September 2014. It also participates in the Insurance Network (IR Network et al., 2015), set up within the $<\mathrm{IR}>$ Business Network, with the aim of developing, sharing, and spreading best practices for IRs in the insurance sector, as well as in a national network of Italian IR adopters.

The Company's IR, prepared at the group level, is incorporated in its financial report. As part of the financial report, the IR formally falls under the responsibility of the Board of Directors. The team in charge of its preparation is the "Group integrated reporting and CFO hub" (hereafter, IR hub). Four persons work in the IR hub: the head of this group, the head of the group integrated reporting framework, and two employees (one of whom is involved in the sustainability office). The Group Chief Financial Officer (CFO), later appointed General Manager, periodically participates to help define the IR content, and multiple departments provide specific information to the IR hub, such as investor relations, sustainability, and communication.

The complete annual integrated report and financial statements consist of (1) a narrative section (i.e., IR) that offers information required by the IIRF, (2) another narrative section that provides information in compliance with financial reporting regulations, and (3) consolidated financial statements (balance sheet, notes, appendices to the notes). The first and second sections together form the management report. The document structure is detailed in all IR, in the section "About this report" (IR 2013 and 2014), "Notes on the management report" (IR, 2015), or "Notes to the report" (2016). In such "About this report" sections, Generali explicitly notes that it prepares and presents the IR in response to both the framework and existing compliance requirements (IR 2013, 2014, 2015 and 2016). Sections that are devoted to its compliance with mandatory legislation are clearly identified in the indexes of the reports.

In reference to the IIRF content elements, the management report is structured to include content required by the framework (IR 2013, 2014, 2015, and 2016), and it incorporates a graph to explain the connection between the sections of the IR and the IIRF content elements. Not every content element merits a specific section; for example, the business model section was introduced in the 2014 reports, and the "risk and opportunities" appeared in 2015. Yet these IR also incorporate sections that are not specifically mandated by the IIRC. The 2014 report includes, for example, a specific section detailing "insurance performance" (distinct from the "our performance" section devoted to financial results). Similarly, the 2015 IR introduces a new section at the start, labelled "Our history."

The guiding principles generally are detailed in the "About this report" (IR, 2013) or the "Notes on the report" (IR, 2014, 2015 and 2016) sections. The 2013 IR claims to comply with the materiality and connectivity guiding principles; in the following year, it declared consistency with all the guiding principles, with explanations for how each principle has been applied. Some explanations are extremely concise (e.g., noting that the "strategic focus and future orientation" principle is applied 
throughout the whole IR in 2013), but others are richer in detail. Nonetheless, the IIRC regards Generali's IR as only partially consistent with the IIRF.2

\section{Findings}

\subsection{Preparers' narrative mode of cognition}

According to staff 1 , Generali started to implement IR by considering that most potential readers were unable to understand its traditional financial reporting, which thus remained largely unread:

"I said to [staff 2]: this report is unreadable! This report does not offer any representation, except the calculative one, that may be of interest for our readers".

The insurance sector in which the Generali operates has technical peculiarities and is particularly complex to be appreciated also for practitioners having a background in finance: Insurance is a "strange animal" (staff 1), and its business models are not well understood, such that they are "not clear even to specialists too" (staff 3). It features reversed revenues and costs, such that the former come before the latter, and its accounting traditions focus mainly on probability and risks. Traditional financial reports seek to offer evidence of the adequacy and correctness of liability calculations and also provide additional documents required by the sector. Together, these reports are particularly suitable for communicating the company's capability to meet policyholders' potential claims and its sufficient revenues to continue covering such claims in the future. This brings many insurer to limit corporate reporting to traditional mandatory disclosure:

\footnotetext{
${ }^{2}$ As indicated in the official IIRC database pertaining to the "emerging practice on integrated reporting" (see http://examples.integratedreporting.org/home), the 2013 IR did not qualify for the database, and the 2014 IR was designated as in compliance only with the principle of connectivity and the fundamental concept of "value creation." In the "Key observations" section of this database, the IIRC affirms that

The business model diagram on pages 22-23 provides a high-level overview of how Generali's strengths create opportunities in the business which, in turn, result in the creation of value for the company's stakeholders. Also shown are a handful of factors in the external environment that impact the company's ability to operate and create value over time. These external factors are discussed in more depth on pages 24-25 and are presented alongside commentary about the risks and opportunities each issue creates for Generali.

In the following year, the database identified the Generali 2015 IR as a best practice for complying with the fundamental concepts of value creation, noting

In pinpointing the circumstances under which the organisation operates as well as the inputs and outputs-outcomes, which it relies on, the Generali's Annual Integrated Report depicts comprehensively its value creation system. An image is presented in which the five primary contextual opportunities and risks ("New Customer Behaviour", "Social and demographic change", "Environmental challenges", "Regulatory developments" and "Uncertain financial and macro-economic landscape") are identified and frame the business model (International $<\mathrm{IR}>$ Framework, para. 4.6). In a similar vein, the material inputs and outputs-outcomes related to each of the six capitals are detailed.

In 2016, the database identified the Generali 2016 IR as an example for connectivity reporting that Generali's Outlook discussion in their 2016 Annual Integrated Report links market developments (of both a macro and industry level) to the company's financial and operational performance (as stated in 4.35 of the <|R> Framework). As per 4.34 of the $<\mathrm{IR}>$ Framework, the section also outlines the challenges and uncertainties Generali will face in regard to their 'Life Segment' and 'Property \& Casualty' lines. The Outlook discussion also demonstrates connectivity (Paragraph 3.8 of the $\langle\mathrm{IR}>$ Framework) by linking changes in the company's external environment to strategic initiatives, namely: asset allocation and diversification in investment; and outlining that shareholder remuneration will increase despite the challenging market environment.
} 
“Our competitors aren't so interested in giving information externally. They just would like to comply with regulation giving mandatory information outside through reports.

They enjoy that the technical content of the Annual report - in the insurance sectoris complex, difficult to be fully understood and boring" (staff 4).

While the traditional financial reports are not considered to be the proper outlets for explaining insurers' corporate governance and strategy (staff 1), Generali has recently experimented a great change in this regard. In the first years of the 2010s, the Company has started with an extraordinary shift in corporate governance, the appointment of a new top management team, and a new corporate strategy. This change sounded unexpected and even anomalous to both preparers and stakeholders, compared with the long, stable tradition of this largest insurance company in the country. This extraordinary change brought the Company's top management to look for the proper way to explain the new vision, related mission and fundamental values underlying the reshaped strategy:

"The idea of corporate strategy had changed and we wanted it to be strongly perceived" (staff 1).

According to Generali preparers, no extant corporate reporting document in the insurance sector was available to address stakeholders' expectations by effectively expressing the strategic "new deal" that the Company adopted, in changing both its strategy and its management (staff 1 ). The new management's idea for addressing stakeholders' expectations was not just to rely on conventional means that companies commonly use (e.g., general assembly, investor day, shareholders' specific meetings) to allow investors and stakeholders to meet the management team.

IR was - and still is - considered the proper outlet to address these accountability tensions by "telling the value creation story" (staff 2). With its narrative nature, IR is considered particularly helpful in explaining "what Generali is and where it aims to go" (staff 1) according to the new strategy. In other words, preparers believe that the narrative nature of IR is fundamental in addressing these accountability tensions.

As continuously confirmed by the preparers, all the Generali IR are conceptualized and prepared as telling a story, "a story about the Company value creation process" (staff 2). The narrative mode of cognition of the preparers is evident within all the reports and strongly emerges in their reasoning about the IR construction. First, the IR provide a sequential order of events as declared at the beginning of the 2015 IR (p. 3): "telling one year of business of one of the major insurance groups worldwide can provide a useful contribution to understanding the status quo, interpret its underlying trends and get into its complexity". This idea is reinforced in the Generali 2016 IR (p. 3): "Our wish is for readers to have a pleasant journey that at the same time will make them reflect and help them interpret the economy and society with a more informed and aware attitude and make them feel surprised that a Generali group report can be much more than a simple report". The IR initial sections present the sequence of significant events explaining what happened in the 
long and recent past; further pages then connect this sequence to the different actions, recent events, and the mental states underlying key historical and current choices. The value creation process, that is at the base of the IR story (i.e. "Our value creation story"), is detailed explicitly in a separate chapter, but it also is made understandable through complementary chapters, which together compose the Company's story. Even parts that are usually calculative (e.g., performance) are instrumental in completing and giving explanation to the Company's story (staff 2).

Second, the IR present the narrators voice, i.e. the voice of the new management offering its view on the value creation process, the renewed strategy and its cascade. Specifically, the IR offers managerial and strategic insights into Generali's actions. As an autobiographical work, the reports also frequently use the first-person plural ("we"), such as sections and paragraphs titled "We, Generali” (2016 IR, p.11), "Our history" (2016 IR p. 24), "How we create value” (2016 IR, p. 20), "Our strategy" (2016 IR, p. 24), "Our governance and remuneration policy" (2016 IR, p. 32), or "Our idea of insurance" (2015 IR, p. 3).

Third, the IR highlight the agentivity of the Company's management in dealing with the complexities linked to the new strategy implementation. All the IR explain the new strategy, its "cascade", and the consequential performances. This approach helps highlight the management intentions and the significance of individual actions in implementing the new strategy. The IR story also explains the risks related to the new strategy implementation in a way that demonstrate how the management is "good" in facing a wide range of risks and "transform them in opportunities for customers and investors" (staff 5).

Fourth, the IR narrative forges a link between the ordinary and the exceptional. The IR identify the change in corporate strategy associated with the corporate governance shift as the extraordinary events to be explained (the strategy change is mentioned at the beginning of the IR). These events are not treated as something to hide. On the contrary, the IR incorporates this exceptional event within the ordinary activities by explaining what the strategy consists of and how it is implemented in the ordinary company's long life. The extraordinary corporate governance shift and corporate strategy change are made "comprehensible" and then explained as falling under the aware domain of the company's management. In other words, Generali preparers strongly perceived these uncommon events and used them to forge a value creation story that make these events seem safer and more familiar.

Corporate strategy and business model are intended as the main "characters" of this value creation story. Every IR "is devoted to explain strategy and to show its cascade: strategy implied two main themes in 2013 and 2014 IR: customer centricity and a greater reward of the shareholder through an enlarged dividend" (staff 1). Furthermore, "We based the IR on our strategic plan and we tried to explain how this strategy has been realized and which strategic initiatives have actually been carried out" (staff 2). In the 2015 IR for example, the strategy was detailed, with new themes, as follows: 
"Innovation, technical excellence, how to deliver on promise towards our customers, personnel engagement and empowerment have become the new issues through which we explained our strategy" (staff 5).

Strategy emerges all along the reports from the beginning (where the main aspects of the new strategy are introduced) to the middle of the story (with a specific section dedicated to the strategy), and implicitly at the end (where the performances are explained as the result of the new strategy implementation), thus favouring the sequential order of the story, agentivity of the Company's management, and the possibility to demonstrate normality despite the extraordinary strategy change.

The other central "character" of the IR value creation story is business model. The business model "character" is helpful in explaining the strategy implementation, thus giving coherence to the whole value creation story. In 2013 and 2014, the business model appeared at the beginning of the IR (in the section "Group presentation"), focused on strengths, the business, and value creation processes. In the 2015 and 2016 IR, it appeared at the end of a longer chapter that also contains descriptions of the external context, vision, missions, values, governance, and reward systems (2015 IR, pp. 22-56), as essential parts of the story. The business model thus provides the conclusion to a discourse about the vision of new company management, seeking to summarize how Generali generates value:

"We decided to speak about vision, missions, values not to be in compliance with the IIRF, but because the new appointed management began a sharing campaign among employees and we spoke about these topics in the paragraph devoted to the value creation process" (staff 6).

All interviews agreed on the fact that a key challenge for preparers is not just to select the "characters" of the story but also to combine and tell story as a whole: reducing complexity and enhancing the attractiveness of the story are essential (staff 2). However, simplicity is difficult, especially in discussions of a new strategy and new management ideas about sophisticated insurance topics, with their own economic principles, unknown technical aspects, and substantial specificity, even though insurance is a commonly purchased product (staff 5 ). In forging the story, IR preparers relied on three main features: (1) how the information is provided, (2) the general design of the document and typographic solutions in the report, and (3) efforts to embed accounting data and ratios into narratives (staff 7). The staff engaged in the IR writing sought a report that would be immediately and easily understood as a whole:

"IR's real nature is its simplicity and its organic proposition. Through IR we could enter in the minds and hearts of people interested to know our company and give them a comprehensive view of our company" (staff 5). 
The general design of the document and the typographic solution offer further tools to improve the narrative by enhancing readability and potentially increasing appreciation among readers. The shared idea is simple:

“... interesting books are made by an appealing layout, nice typographic solutions, figures and picture explaining the concepts you would like to expose. Think to the medieval incunabula: they were quite pretty and people were interested in them. But if you think about many actual financial reports, nobody likes to read them: we have to do the opposite with our IR" (staff 1).

Many companies produce financial reports that feature the same layout year after year, such that the documents seem the same, as if the preparers had simply completed a form. Thus,

"We had been having the need to improve our annual Financial Report for a long while. [...] We decided to change the format, the pictures and the images we used in the documents. We put in the Financial Report also the faces of our internal staff to make the reader understand that our company is made by people" (staff 1).

In Generali's IR, typographic solutions and the layout are more than just the printer's preference; they offer an effective way to make the IR story more understandable and pique the curiosity of many readers, potentially increasing their attention to the new strategy of the company. Furthermore, it continuously changes the layout, expressions, pictures, and sentences, even if the vision, mission, and values remain the same.

"We create a renewed document every year to reflect the strategy and business model themes into appealing images and a layout that can catch readers' interest.

This work is an important part to get the target of having a readable and interesting document" (staff 6).

Finally, the IR team must find a way to present material accounting data in a narrative document. The preparers thus had to select which KPIs to include; this debate remains an open question, even in the IR Insurance Network, because financial reports often include a lot of quantitative data about insurance liabilities that can make them highly technical:

"In the Generali IR, the selection of the KPIs and the accounting data is in compliance with the main task of IR: to tell a story. We have to extrapolate, among the huge amount of data we were provided by different internal departments, those able to provide helpful insights to the value creation process and to the strategy, and then we explained the data with narrative discourses about their significance. Material data to be presented in our IR are just those able to explain our strategy and the value creation process" (staff 7 ).

Despite the deep reasoning about the most appropriate way to forge a story able to address the accountability tensions perceived by preparers, these latter did not consider sustainability as a relevant character of the story. In the preparers' explanation of how they construct the Company 
value creation story, sustainability is marginalized, with the assertion that the organizational context is "not ready" to include sustainability issues. The sustainability office is part of a different division, and reaching common ideas or truly integrated thinking on sustainability topics is a distant goal: "Sustainability has to be integrated. It's really a great job to do. In Generali, IR advancement came before a full integration of the different offices occurs" (staff 8). Nonetheless, the Company is "planning to merge sustainability into the IR in next years" (staff 1). At this stage, the IR includes different "pre-financial indicators" such as a net promoter score, satisfaction ratio, or promoting service index:

"This on-going effort must be in tune with the strategy, which remains our principal story to be told, otherwise it is not material to deal about sustainability. For instance, a first theme to be developed is human capital, considering that in 2015 we developed the first "engagement survey": its results gave us some indications to redefine shortrun and medium-run strategies. We can implement new figures in our IR if they have an impact on strategy" (staff 2).

\subsection{Socializing accountability}

\subsubsection{The dialogue with financial stakeholders}

According to the preparers, the IR narrative provides a mean to enable or extend a dialogue with stakeholders to address their needs, suggestions, advice, and concerns. All interviewees agree about this main purpose of communicating better with many kinds of investors, by providing them with a qualified, trustable, simple story about value creation after an extraordinary event. Thus, IR information primarily is addressed to investors and the financial community at this stage, according to the shared opinions of the top staff. The internal functions involved in the relationship with investors include the IR team, investor relations, communications, and finance; the latter is led by the CFO but under the direct control of the CEO.

"The IR project that was able to give a new turn to renewed need of information about our strategy and our business model. We had three kind of external stakeholders we mainly looked at: debt investors; equity investors; rating agencies. The first addressees of the IR are these three different investors" (staff 1).

Interviewees reveal that these three kinds of "financial stakeholders" attract special attention from preparers and have a converging interest in the information available in the IR. Information about business models and strategy would not appear in traditional reports. However, debt investors, who tend to be the most sophisticated, interested, and technically prepared recipients, need insights into the possibility of a "loss default," so they seek to know (by reading the IR) what the corporate strategy is, where corporate investments are going, and whether any interruption in going concerns is possible. As the interviewees explain, 
"Equity investor is less sophisticated, even if usually one is convinced about the opposite" (staff 1).

"But even those are our target, because they look for information if they should invest in Generali or not. And they need to know the business model. Through the IR is rather simple to understand it" (staff 3 ).

Another type of stakeholder is rating agencies, which are relatively fewer than the vast pool of investors but skilful and influential. Managers thus devote special attention to them:

"Together with the investors, they are interested to know what are the main drivers able to create value for the company, considering the great amount of relationships that our company has. To achieve this purpose, telling the strategy as well as explaining the direction where you are going and the targets you would like to get, are the best ways to give disclosure of what you are doing: this is the reason why the IR is focused on strategy" (staff 7).

According to staff 2 , the IR is apt to bring the financial community closer and keep the conversation alive by encouraging investors to use it (instead of other reports) efficiently, to support their analyses and gain an overview of the Company and group.

"I don't know if IR is the sole channel to inform investors, but everybody is really reading this document and this is quite new in our experience" (staff 3 ).

Joining satisfaction and pride in telling its own story through the IR, staff 1 adds:

"In an analyst meeting I see our IR underlined by participants that follow the event. They don't pose questions, because they read the IR".

The purpose of the management effort thus has been achieved.

"Among many feedbacks, we collected opinions and comments by our investors that are important stakeholders for us and since the first IR edition they follow changes and improvements of the final annual documents. Recently many of them told us that they appreciated the change in information provided as they found our IR simpler and more usable. The technician aspects (if required) were satisfied by the accompanying supplemental disclosure we provide with an external file, that contains a lot of financial information. The opportunity to use a shorter document providing a very sound disclosure makes them really satisfied. We collected also positive feedbacks in the Insurance Network: one of the first initiative we organized was to call "ethic" and common investors to these meetings and they all shared with us their satisfaction in this new way to provide information" (staff 6).

The IR preparers narrate how they manage to make the financial community closer. They stress the importance to provide them with transparent, timely and regular communication and but also to have conversations with them through investors day, roadshows, meetings and conferences. They 
organized about 30 events every year to come into contact with the financial community and the IR is considered an important topic of conversation and debate during such meetings (staff 3 ).

\subsubsection{The dialogue with nonfinancial stakeholders}

The IR preparers agreed that IR facilitates the socializing accountability effect toward nonfinancial stakeholders too. There is an overall interest in the Generali IR across many kinds of stakeholders:

"With our report, we would like to join not just the investors, but our customers, our current or future employees, our strategic partners as we are really interested to meet the needs of our stakeholders, to explain where we were going, where we are, if we delivered our promise towards them getting the targets, and to give disclosure to our results, explaining them. This job has been conceived in an international perspective, as we are not just involved in domestic issues" (staff 2).

Nonfinancial stakeholders mentioned during interviews include customers, strategic partners, employees and nonaccounting departments, academics, and students. IR preparers believe that a clear, simple explanation of the new strategy and business model allows the Company to build or expand a dialogue with such stakeholders and favour commitment to the shift in strategy and corporate governance. More generally, the IR embeds information about strategy, business model, value creation which does not appear frequently in other reports, and this may open new conversations between the firm and nonfinancial stakeholders (staff 4).

"The Financial report is long, complicated, ceremonial and boring, while the effort to get a new tool, the IR, enlarges its use to many people and makes our story much more interesting" (staff 8).

In addition, IR narrative helps overcoming nonfinancial stakeholders' lack of knowledge of the insurance business model (staff 2). Through IR, a more aware and stable relationship could take place as they understand their role in the value creation process (staff 5 ). In this sense, IR acts as a fundamental tool to reinforce stakeholders' sense of belonging.

"The IR sends immediate, comprehensible messages to other (external) stakeholders who find quick, reliable information useful to continue and expand their relationship with the firm and who also might gain a sense of pride to be connected with it" (staff 6).

Among different nonfinancial stakeholders, IR particularly aims at increasing internal conversation, such as among existing employees but also with new recruits to the organization. The connection achieved results from deep, intertwined relationships among the staff involved in the IR preparation. The IR indeed tell the story of all the people belonging to the group;

"Everyone is important in its production and has to pick out, from the huge amount of information available, what is useful to tell the company strategy, the ways in which 
strategic targets have been reached and the joint effort to convey different know-how and abilities to get these targets" (staff 7).

The main work of the IR team is to "break the silos" between different areas and cultures in the Company, then make sure the information is connected and comprehensible beyond the corporation. This effort gets worked out through operational plans, which ensure that bottom-up processes and their intertwined connections are relevant and continuous, requiring dialogue among various company offices. This organizational solution also facilitates the progressive sharing of thoughts and opinions among employees, managers, and the board. Deeper relationships among the personnel are strongly researched and expected by IR preparers, through the introduction and the diffusion of the IR document (staff 1). Internal debate is encouraged, at any corporate level starting with the staff that supplies the information used to prepare the IR and then spreading to other departments across countries (staff 2).

"We are now preparing the IR, and its work outcomes before a truly integrated thinking has developed among different corporate departments and staff. So, building an IR will help developing integrated thinking" (staff 1).

Finally, IR preparers continuously gather comments about IR from different potential readers, then aim to leverage this information to improve the readability, comprehensibility, and usefulness of the $\mathrm{IR}$, to better satisfy the addressees. For example, the IR team visits university lectures and ask students to review the IR, who then provide feedback. The IR team also invites academics, practitioners, and colleagues from other companies to review the report. Its participation in the IR Insurance Network means that the Company engages in frequent debates with advisors, other IR preparers, auditors, academics, and other users. Financial and nonfinancial stakeholders thus feel closer to the Company. According to IR preparers, they think they are part of the value creation story, with greater awareness of their role in the business model. Furthermore, IR preparers believe the IR readers appreciate this effort, because this way of telling the Generali's story allows them to understand the Company's choices related to strategy and management changes.

"Getting better is the leitmotiv shared by the IR team - that is, to tell the story of the value creation process and the strategy of the company better, by renewing the $I R$ every year" (staff 2).

\section{Discussion}

The idea that IR could enhance corporate accountability remains largely conceptual, rather than being explored in terms of experiences and the actual engagement of actors involved in accountability relationships. The present paper tries to fill this gap by empirically exploring how IR preparers experience accountability while preparing their IR. In particular, it investigates the IR as a potential source of socializing accountability toward investors and other stakeholders. 
In the viewpoint of Generali IR preparers, the IR has a crucial role with regard to enhancing accountability, as reflected in the many meetings and discussions of actors directly involved in its preparation. The construction of the IR continues to stimulate deep reasoning processes about the construction of the message that the company uses to face accountability challenges linked to the renewed strategy and the changes in the corporate governance and management structure. The results show that these tensions are perceived by preparers not only in connection with the first adoption of the report (2013) but also in subsequent years. The IR implementation thus entails a thorny reasoning process about discharging accountability (Abeysekera, 2013), by reducing the accountability tensions generated by the Company's "traditional" financial reporting. In turn, IR implementation has offered directors, managers, and employees an opportunity to discuss how to communicate institutionally with investors and other stakeholders, as well as to align corporate reporting with their increasing information needs (KPMG, 2014; IIRC, 2015). The IR implementation has also provided an opportunity to face challenges inherent to the insurance sector, such as the complexity of the business model and regulatory evolutions (IIRC et al., 2015). The preparers' reasoning about how $I R$ can address accountability tensions, which they perceive as relevant in their reporting context, weakens the argument of IR as "business as usual" practice (Brown and Dillard, 2014 , p. 1120) and offers some optimism about IR's potential for "redefining" corporate accountability (Busco et al., 2013).

The findings show that IR is able to produce socializing effects for a plethora of stakeholders. Investors, both debt holders and equity investors, analysts, and rating agencies, as well as customers, strategic partners, employees, academics, and students are all identified as intended recipients, and traces of enhanced dialogues between the Company and all of these stakeholders appear in the study data. Such facilitated dialogues are evident in the remarkable appreciation that IR users expressed directly to staff involved in preparing the IR, as well as to the persons working in the investor relations and communication departments. Even employees of Generali consider IR beneficial to their efforts to understand the Company's strategy and its effects on their work. Therefore, IR can produce socializing accountability effects for investors (debt holders and equity investors), other financial stakeholders (analysts and rating agencies), and nonfinancial stakeholders. The main nonfinancial stakeholders the preparers address are employees, followed by consumers, strategic partners, academics, and students. The involvement of these various stakeholders in the process of IR construction (e.g., consideration of students' comments to define IR subjects) is a sign of a willingness to attract and address more than just investors.

However, investors and the other financial stakeholders remain the key stakeholders. This study does not mean to suggest that IR is intended to be more beneficial for financial stakeholders than for nonfinancial stakeholders; the preparers believe the latter groups gain important benefits from reading the IR. Rather, investors and other financial stakeholders continue to represent the primary recipients of the report, in line with the aim of the IR, according to the IIRC: "The primary 
purpose of an integrated report is to explain to providers of financial capital how an organization creates value over time" (IIRC, 2013a, $\S 1.7$ ). This conformity reduces the actual possibility that IR can meet nonfinancial stakeholders' expectations and enhance a dialogue with them though, to the extent that their expectations diverge from financial stakeholders' (de Villiers et al., 2016, Rowbottom and Locke, 2016). Both financial and nonfinancial stakeholders likely have basic, convergent expectations about the Company's strategy and its effects. For example, the interviewees for this study believe that all stakeholders expect broader content (e.g., strategic considerations, business model disclosures) and reduced reporting complexity (plainer, more friendly language). Conversely, they are unlikely to converge in their expectations about more specific issues, such as understanding how the Company's strategy affects the six capitals depicted by the IIRC. In this respect, this study aligns with previous critical studies arguing that the IIRC's concept of value is "value for investors" and that organizations address nonfinancial stakeholders' expectations only to the extent that investors' needs are not contradicted (e.g., Higgins et al., 2014; Flower, 2015, Thomson, 2015). This cast some doubts on the actual possibility for IR to extend corporate accountability toward a broad range of nonfinancial stakeholders.

According to Boland and Schultze (1996), the socializing effects associated with IR are strongly influenced by the narrative mode of cognition enabled by the Company's IR preparers, which resulted in the narrative shift in Generali's corporate external reporting. Critical studies indicate that the narrative mode of accountability is "consistently undervalued and often suppressed" (Boland and Schultze, 1996, p. 62), relative to calculative accountability (Lowe et al., 2012; McKernan and McPhail, 2012), but empirical findings confirm a narrative turn in accounting practices (Beattie and Smith, 2013; Beattie, 2014). Generali did not support an evolution from a calculative form of accountability to a more narrative one simply by adding a new report (the $I R$ ) to existing ones (financial and sustainability reports); it transformed the "classic" management commentary of the financial report into an IR, which became the first part of its financial report. It prepared the IR explicitly to tell its value creation story, based on the new strategy, without being particularly worried about performance indicators or confirming valuable achievements. In this view, the IR is not a tool to complement accounting data; rather, accounting data serve to support descriptive explanations of the implementation process for the new strategy.

Forge as a storytelling, the IR acted as a carrier of socializing accountability effects; it succeeded in addressing the accountability tensions that the preparers encountered. The accountability tensions diminished due to storytelling that narratively explained how the Company was able to implement its new strategy and thus generate significant achievements, through the efforts of all its managers. In line with Bruner's (1990) argument, the IR narratives, based on the preparers' modes of cognition, make comprehensible the uncommon events represented by a contingent corporate strategy change and the inherent complexity of the insurance sector's business model. 
Strategy and business model are fundamental concepts or content elements in the IIRF (2013), and they serve as core components of the preparers' storytelling too. Previous studies criticise the viability of incorporating business model disclosures into external reporting (e.g. Page, 2014; Melloni et al., 2016), but the preparers in this study reveal the widely perceived need to expand traditional financial reporting and offer a more holistic description of corporate doings. The IR preparers appear unconcerned with identifying the "best" technical solution to disclose the business model in terms of the single technical elements to be depicted; they care about the need to explain plainly the core issues of corporate activities, and they believe that narrative elements produce greater understanding of how a company achieves its performance.

In contrast, sustainability remains marginalized in the construction of Generali's IR. Even though the Company has been publishing a sustainability report for 13 years (even after its IR adoption), sustainability issues only marginally contribute to its story in the IR. The IIRC suggests a sustainability perspective for IR, due to its potential to encourage consideration of long-term, nonfinancial aspects (IIRC, 2013b). However, the interviews demonstrate that the IR has not been imagined or constructed to "integrate" corporate sustainability challenges within the narrative of the company's value creation story. The separation of the sustainability office from the IR hub may have lessened these sustainability inclinations. Prior research indicates that IR needs integrated thinking (Adams, 2013, 2015), but the interviewees suggest an inverse relationship: IR helps develop integrated thinking within the Company, which still is not widespread across departments. Their acknowledgement that IR enhances dialogue across the departments involved in the IR preparation and between preparers and the departments that receive the "final" report testifies to the potential of IR as an integrated thinking facilitator. However, this achievement has yet to emerge for the sustainability department. Thus, IR content appears driven more by the specific organizational context than by IIRF guidelines (Thomson et al., 2014), as revealed in the ways in which the preparers' views, rather than the IIRF, inform the construction of the Company's value creation story in the IR.

Although the IIRC's principle original objective was to enhance sustainability (Flower, 2015; Thomson, 2015), this study demonstrates that companies participating in the IIRC pilot program may be focused more on moulding their value creation story than on demonstrating their sustainability efforts. This is not to say, obviously, that Generali is not involved in sustainability; its prolonged preparation of sustainability reports reveals its willingness to disclose its sustainability policies and achievements. However, the Company does not consider sustainability a "character" in the story it tells through the IR. As such, it does not "disclose how they define value" (Adams, 2013, p. 52) and could have difficulties in demonstrating its use of the term value (creation) as value for society (Flower, 2015).

In narratively moulding the value creation story within the $\mathrm{IR}$, the preparers indicate their involvement in reducing the complexity and increasing the attractiveness of external reporting; they 
believe that IR is a useful reporting format for achieving both these goals. Thus, the IR preparers worked to create narrative sections that explain the "numbers" (mostly, accounting data) in a simple way. Numbers are important but insufficient to tell the value creation story. The use of less technical language serves this reporting purpose (Lueg et al., 2016), and reducing report complexity is emerging as a strong motive for IR implementation (Rowbottom and Locke, 2013), in line with other practitioners' considerations (KPMG, 2014).

The narrative turn solicited by IR enables a shift toward a socializing form of accountability (Roberts, 1991, 1996; Boland and Schultze, 1996), in the sense of facilitating a meaningful dialogue with the IR's intended users. As indicated by Boland and Schultze (1996) in their criticism of Roberts's $(1991,1996)$ argument about the individualizing and socializing effects of accounting, socializing forms may occur even in formal or hierarchical accountability contexts, such as corporate external reporting. The mode of cognition (and representation), not the specific media, moulds the accountability relationship between the accountor and the accountee.

\section{Conclusion}

In Generali, IR implementation involves a thorny reasoning process about how to discharge accountability. Preparers are particularly interested in addressing accountability tensions that derive from a contingent corporate strategy change and the inherent complexity of the insurance sector's business model. They believe that IR represents the perfect outlet for resolving these tensions. Their narrative mode of cognition drives them to craft the IR in a way that renders the contingent events comprehensible, recounting these events as under the control of the Company's management. Some "characters" remain suppressed in constructing the IR value creation story; sustainability issues are not part of this story, whereas value creation, strategy, and the business model are considered crucial for explaining how the Company deals with competitive challenges. As a result, the IR facilitates the socialization of accountability effects, by enhancing the dialogue between the Company and the IR's intended addressees. Although the stakeholders the preparers address are not only financial ones, investors and the other financial stakeholders remain the key stakeholders whom interviewees mention when speaking about IR implementation. Preparers do not recognize the need to customize the IR according to the different expectations of financial and nonfinancial stakeholders.

With its empirical findings, this article contributes to the emerging debate on IR in several ways. First, it offers insights into how the implementation of IR can stimulate reconsiderations of and changes in corporate accountability. In particular, IR can enhance accountability by facilitating dialogue with various stakeholders, even if investors and other financial stakeholders remain the primary addressees. In this respect, this research contributes to the debate about the possibilities (and limits) of IR for enhancing corporate accountability, extending beyond the largely conceptual approaches that thus far have mainly investigated the shifting scope and content of the IIRF. 
Second, this research confirms that the IR project facilitates "narrative-based reporting" (Beattie and Smith, 2013, p. 118), in opposition with the proliferation of (and threats associated with) calculative forms of accountability (Lowe et al., 2012; McKernan and McPhail, 2012). It thus clarifies that topics that are not traditionally addressed by financial reporting but that are central to the IIRF (e.g., strategy, business model) can help force meaningful narratives of the company's value creation story.

Third, the present research elucidates the role of preparers and reveals that their (narrative) mode of cognition can orient the content of the IR and address accountability tensions. In this respect, this article extends emerging literature that has started to elucidate preparers' perceptions of IR adoption (e.g., Rowbottom and Locke, 2013; Higgings et al., 2014; Lodhia, 2015; Lueg et al., 2016).

Fourth, this empirical analysis suggests that IR preparers do not feel particularly constrained by the guiding principles or content elements stated by the IIRF; they seek (and declare) their compliance, but the IIRC considers Generali's IR compliance only partial, as detailed in footnote 2. In line with Thomson et al.'s (2014) findings, preparers' choices of accountability content are not driven forcibly by the IIRF; they construct the IR text to enhance their dialogue with various stakeholders (e.g., customers, strategic partners, employees of non-accounting departments, academics, students). This finding encourages further exploration of the relationship between IR and accountability, especially with regard to specific IR preparers' experiences, to go beyond the IIRC's views. Previous research criticizes the IIRF for its primary focus on the information demands of capital providers (Deegan, 2013; Brown and Dillard, 2014; Flower, 2015; Thomson, 2015); the present research confirms this argument but also suggests the need to investigate how preparers actually engage and comply with the IIRF.

This research project includes several limitations too. The subjectivity of the interview analysis and interpretation means that biases could affect the exploration of how preparers experience accountability, though the authors tried to pose questions indirectly and discussed the findings among themselves (after individual analyses). The replies from the first respondents also influenced the selection of subsequent respondents, but the most recent interviewees consistently suggest the same informants. This study does not provide any analytical investigation of how Generali's IR complies with the IIRF or other reporting standards and guidelines and an in-depth analysis of the content of the corporate reports (e.g., sustainability report) is out of the scope of the present work. Another limitation relates to the deliberate decision to focus on preparers' views of accountability, without including users' perspectives. The future research opportunities are thus broad, including deeper explorations of users' accountability perspectives.

\section{References}

Abeysekera, I. (2013), "A template for integrated reporting", Journal of Intellectual Capital, Vol. 14, No. 2, pp. 227-245. 
Adams, C.A. (2013), Understanding integrated reporting: the concise guide to integrated thinking and the future of corporate reporting, Dō Sustainability, Oxford.

Adams, C.A. (2015), "The international integrated reporting council: a call to action", Critical Perspectives on Accounting, Vol. 27, pp. 23-28.

Atkins, J. and Maroun, W. (2015), "Integrated reporting in South Africa in 2012. Perspectives from South African institutional investors", Meditari Accountancy Research, Vol. 23, No., pp. 197-221.

Beattie, V. (2014), "Accounting narratives and the narrative turn in accounting research: Issues, theory, methodology, methods and a research framework", The British Accounting Review, Vol. 46, No. 2, pp. 111-134.

Beattie V. and Smith S.J. (2013), "Value Creation and Business Models: Refocusing the Intellectual Capital Debate", British Accounting Review, Vol. 45, No. 4, pp. 243-254.

Beck, C. Dumay, J. and Frost, G. (2015), "In pursuit of a 'single source of truth': from threatened legitimacy to integrated reporting", Journal of Business Ethics, doi.10.1007/s10551-014-2423-1.

Boland, R. and Schultze, V. (1996), "Narrating accountability: Cognition and the production of the accountable self", in Munro, R. and Mouritsen J. (Eds.), Accountability: Power, ethos and the technologies of managing, International Thomson Business Press. London, pp. 62-82.

Brown, J. and Dillard, J. (2014), "Integrated reporting: On the need for broadening out and opening up", Accounting, Auditing \& Accountability Journal, Vol. 27, No. 7, pp. 1120-1156.

Bruner, J.S. (1986), Actual minds, possible worlds, The Jerusalem-Harvard lectures, Harvard.

Bruner, J.S. (1990), Acts of meaning, Harvard University Press, Harvard.

Bruner, J.S. (1991), "The Narrative Construction of Reality", Critical Inquiry, Vol. 18, No. 1, 1-21.

Busco, C., Frigo, M. L., Quattrone, P., and Riccaboni, A. (2013), Integrated reporting. Concepts and Cases that Redefine Corporate, Springer, London.

Chaidali, P.P., and Jones, M.J. (2017), "It's a matter of trust: Exploring the perceptions of Integrated Reporting preparers", Critical Perspectives on Accounting, Vol. 48, pp. 1-20.

Cheng, M., Green, W., Conradie, P., Konishi, N. and Romi, A. (2014), "The International Integrated Reporting Framework: key issues and future research opportunities", Journal of International Financial Management \& Accounting, Vol. 25, pp. 90-119.

CIMA (2014), "Tomorrow's company and IIRC. Using integrated reporting to help create value and effectively tell the full story", https://www.cimaglobal.com/Research--Insight/Using-integrated-reportingto-help-create-value-and-effectively-tell-the-full-story/.

Coghlan, D. and Brydon-Miller M. (2014), The SAGE Encyclopedia of Action Research, SAGE, Thousand Oaks (CA).

Deegan, C. (2013), "The accountant will have a central role in saving the planet... really? A reflection on 'green accounting and green eyeshades twenty years later'”, Critical Perspectives on Accounting, Vol. 24, No. 6, pp. 448-458.

de Villiers, C., Rinaldi, L. and Unerman, J. (2014), "Integrated Reporting: Insights, gaps and an agenda for future research", Accounting, Auditing \& Accountability Journal, Vol. 27 No. 7, pp. 1042-1067.

de Villiers, C., Rinaldi, L. and Unerman, J. (2015), "Special issue on Case study insights from the implementation of Integrated Reporting", http://www.emeraldgrouppublishing.com/authors/writing/ calls.htm?id=6194.

de Villiers, C., Venter, E.R. and Hsiao, P.C.K. (2016), "Integrated reporting: background, measurement issues, approaches and an agenda for future research", Accounting \& Finance, doi.rg/10.1111/acfi.12246.

Dumay, J. Bernardi, C., Guthrie G. and Demartini P. (2016), "Integrated reporting: A structured literature review", Accounting Forum, Vol. 40, No. 3, pp. 166-185.

EFRAG (2013), Getting a better framework: The role of the business model in financial reporting, https://www.efrag.org/Assets/Download?assetUrl=\%2Fsites\%2Fwebpublishing\%2FSiteAssets\%2FB ulletin\%2520Getting\%2520a\%2520Better\%2520Framework\%2520\%2520The\%2520Role\%2520of\%2520the\%2520Business\%2520Model\%2520in\%2520Financial\%25 20Reporting.pdf..

Gray, R. (2006), "Social, environmental and sustainability reporting and organisational value creation? Whose value? Whose creation?", Accounting, Auditing \& Accountability Journal, Vol. 19, No. 6, pp. 793-819.

Gray, R., Owen, D. and Maunders, K. (1988), "Corporate social reporting: emerging trends in accountability and the social contract", Accounting, Auditing \& Accountability Journal, Vol. 1, No. 1, pp. 6-20.

Flower, J. (2015), "The international integrated reporting council: a story of failure", Critical Perspectives on Accounting, Vol. 27, 1-17.

Higgins, C., Stubbs, W., \& Love, T. (2014). "Walking the talk(s): organisational narratives of integrated reporting", Accounting, Auditing \& Accountability Journal, Vol. 17, No. 7, pp. 1090-1119.

Holland, J. (2005), "A grounded theory of corporate disclosure", Accounting and business research, Vol. 35, No. 3, pp. 249-267. 
IASB (2010), IFRS practice statements, management commentary. A framework for presentation. http://www.ifrs.org/Current-Projects/IASB-Projects/Management-Commentary/IFRS-Practice-

Statement/Documents/Managementcommentarypracticestatement8December.pdf.

IIRC (2013a), International Integrated Reporting Framework, http://integratedreporting.org/wpcontent/uploads/2015/03/13-12-08-THE-INTERNATIONAL-IR-FRAMEWORK-2-1.pdf .

IIRC (2013b), Business and Investors Explore the Sustainability Perspective of Integrated Reporting. http://www.theiirc.org/wp-content/uploads/2013/12/IIRC-PP-Yearbook-2013 PDF4 PAGES.pdf.

IIRC (2015), Creating Value. Integrated Reporting <IR $>$ and Investor Benefits, http://integratedreporting.org/wp-content/uploads/2015/12/Creating-Value-Integrated-Reporting-andinvestor-benefits.pdf.

IASB and IIRC (2013), Memorandum of understanding-integrated corporate reporting, http://www.ifrs.org/Use-around-the-world/Documents/MoU-IIRCand-IFRS-Foundation-February2013.pdf.

Ignatow, G. and Mihalcea, R. (2016), Text Mining: A Guidebook for the Social Sciences, SAGE, Thousand Oaks (CA).

IR Network, Aegon, Generali and Mazard (2015), Value creation in the insurance and reinsurance industry http://integratedreporting.org/wp-content/uploads/2015/03/Business-Case-IR-Insurance-IndustryNetwork-2015.pdf.

Jameson, D.A. (2000), "Telling the investment story: A narrative analysis of shareholder reports", The Journal of Business Communication, Vol. 37, No. 1, pp. 7-38.

Jensen, J.C. and Berg, N. (2012), "Determinants of traditional sustainability reporting versus integrated reporting. An institutionalist approach", Business Strategy and the Environment, Vol. 21, No. 5, pp. 299-316.

KPMG (2014), Corporate reporting reform - Better alignment with investor decision making, http://group100.com.au/wp-content/uploads/2015/03/kpmg-corporate-reporting-reform-alignmentinvestor-decision-2014.pdf.

Lodhia, S. (2015), "Exploring the transition to integrated reporting through a practice lens: an Australian customer owned bank perspective", Journal of Business Ethics, Vol. 129, 585-598.

Lueg, K., Lueg, R., Andersen, K. and Dancianu, V. (2016), "Integrated reporting with CSR practices. A pragmatic constructivist case study in a Danish cultural setting", Corporate Communications: An International Journal, Vol. 21, No. 1, pp. 20-35.

McKernan, J.F. and MacLullich, K. (2004), "Accounting, love and justice", Accounting, Auditing \& Accountability Journal, Vol. 17, No. 3, pp. 327-360.

McKernan, J.F., McPhail, K. (2012), "Editorial - Accountability and Accounterability", Critical Perspectives on Accounting, Vol. 23, pp. 177-182.

Melloni, G., Stacchezzini, R. and Lai, A. (2016). "The tone of business model disclosure: an impression management analysis of the integrated reports", Journal of Management \& Governance, Vol. 20, No. 2, pp. 295-320.

Messner, M. (2009), "The limits of accountability", Accounting, Organizations and Society, Vol. 34, No. 8, pp. 918-938.

Milne, M.J. and Gray, R. (2013), "W(h)ither ecology? The triple bottom line, the global reporting initiative, and corporate sustainability reporting", Journal of business ethics, Vol. 118, No. 1, pp. 13-29.

O'Dwyer, B. and Unerman, J. (2008), "The paradox of greater NGO accountability: A case study of Amnesty Ireland", Accounting, Organizations and Society, Vol. 33, No. 7, pp. 801-824.

O'Hearne, G. and Pauffley, R. (2014), "Integrating the new science of reporting and the ancient art of storytelling", http://www.pauffleyandcompany.com/downloads/GBS The\%20Reporting\%20Times October 2014-12.pdf.

Page, M. (2014), "Business models as a basis for regulation of financial reporting", Journal of Management \& Governance, Vol. 18, No. 3, pp. 683-695.

PwC (2007), "Narrative reporting. Give yourself a head start", https://www.pwc.com/gx/en/auditservices/corporate-reporting/assets/pdfs/narrative-reporting.pdf.

Reuter, M., and M. Messner, (2015), "Lobbying on the integrated reporting framework: an analysis of comment letters to the 2011 discussion paper of the IIRC", Accounting, Auditing \& Accountability Journal, Vol. 28, pp. 365-402.

Rinaldi, L., Unerman, J. and Tilt, C. (2014), The role of stakeholder engagement and dialogue within the sustainability accounting and reporting process, in Bebbington, J., Unerman, J. and O'Dwyer, B., Sustainability Accounting and Accountability, second ed., Routledge, London, pp. 86-107.

Roberts, J. (1991), "The possibilities of accountability", Accounting, Organizations and Society, Vol. 16, No. 4, pp. 355-368. 
Roberts, J. (1996). "From discipline to dialogue: individualizing and socializing forms of accountability" in Munro, R. and Mouritsen J. (Eds.), Accountability: Power, ethos and the technologies of managing, International Thomson Business Press. London, pp. 40-61.

Roberts, J. and Scapens, R. (1985), Accounting systems and systems of accountability-understanding accounting practices in their organisational contexts, Accounting, organizations and society, Vol. 10, No. 4 , pp. 443-456.

Rowbottom, N. and Locke, J. (2016), "The emergence of IR", Accounting and Business Research, Vol 46, pp. 83-115.

Shearer, T. (2002), "Ethics and accountability: from the for-itself to the for-the-other", Accounting, Organizations and Society, Vol. 27, No. 6, pp. 541-573.

Sinclair, A. (1995), "The chameleon of accountability: Forms and discourses", Accounting, organizations and Society, Vol. 20, No. 2, pp. 219-237.

Stubbs, W. and Higgins, C. (2014), "Integrated reporting and internal mechanisms of change", Accounting, Auditing \& Accountability Journal, Vol. 27, pp. 1068-1089.

Thomson, I. (2015), "But does sustainability need capitalism or an integrated report'a commentary on 'The International Integrated Reporting Council: A story of failure' by Flower, J.", Critical Perspectives on Accounting, Vol. 27, pp. 18-22.

Thomson, I., Grubnic, S., and Georgakopoulos, G. (2014), "Exploring accounting-sustainability hybridisation in the UK public sector", Accounting, Organizations and Society, Vol. 39, No. 6, pp. 453-476.

Van Bommel, K. (2014), "Towards a legitimate compromise? An exploration of integrated reporting in the Netherlands", Accounting, Auditing \& Accountability Journal, Vol. 27, No. 7, pp. 1157-1189. 


\section{Table 1. Main issues discussed during the interviews}

1. How long have you been working in Generali and what is your position within the company?

2. Why has Generali adopted the IR and what are the most important benefits related to such adoption?

3. What are the main challenges arising from IR adoption?

4. Who are the intended addressees of your IR? Investors? Others?

5. How do you address users' specific information needs? Do you collect feedback from them?

6. Who are the main proponents of IR adoption within the company?

7. Who are the actors/offices directly involved in the preparation of the report?

8. How do these actors/offices interact with other offices in order to collect information?

9. What is the role of governance bodies and top management in defining the topics and the language of the report?

10. How are the topics of IR selected? Have these topics changes over time?

11. Are there any topics that were excluded from or marginalized within the IR? Why?

12. To what extent Generali follows the IIRC framework?

13. Which are the main sources (e.g. sustainability report; governance report; internal documentations, etc.) for drafting the report?

14. How is the language of the report chosen?

15. Have IR content elements and language changed over time? Why?

16. What has been the evolution of the IR in Generali and what will be in the future?

17. Which kind of relationships are favoured by IR with investors and other external stakeholders?

18. Which kind of relationships are favoured by IR with internal stakeholders? 